Bangladesh J. Sci. Ind. Res. 43(1), 103-116, 2008

\title{
Investigations on the Redox Characteristics and Hydrogen Evolution Efficiencies of Pd and Mo Deposited Pd Electrodes in Alkaline Electrolyte
}

\author{
M. Ashraful Islam Molla ${ }^{a}$, Mithun Sarkera and A.K.M. Fazle Kibriab \\ ${ }^{a}$ Department of Applied Chemistry and Chemical Technology, Dhaka University and \\ ${ }^{b}$ Chemistry Division, Atomic Energy Centre, Ramna, Dhaka-1000, Bangladesh
}

\begin{abstract}
Redox behaviors and hydrogen evolution efficiencies of Pd and Mo deposited Pd electrodes have been investigated in 30wt.\% KOH electrolyte by cyclic voltammetry. Cyclic voltammograms of Pd electrode in between the potential range $-1.05 \mathrm{~V}$ to + $0.75 \mathrm{~V}$ showed two couples of redox peaks for the transformations of $\operatorname{Pd}(0) \leftrightarrow$ $\mathrm{Pd}(\mathrm{OH})_{2}$ and $\mathrm{Pd}(\mathrm{OH})_{2} \leftrightarrow \mathrm{PdOOH}$, an anodic peak for the desorption of diffusional hydrogen $\left(\mathrm{d}_{\mathrm{H}}\right)$ and hydrogen and oxygen evolutions at the terminal potential regions. Hydrogen evolution efficiency found decreased with time and then reached to a stable condition after 35 minutes. In presence of deposited Mo, the electrode stable condition appeared after 10 minutes only. Pd found predominates over deposited Mo. Both the $\mathrm{Pd}(0) \leftarrow \mathrm{Pd}(\mathrm{OH})_{2}$ and $\mathrm{Mo}(0) \leftarrow \mathrm{Mo}(\mathrm{OH})_{2}$ transformations appeared at the same potential value. Mo stopped the movement of hydrogen adsorption and absorption region of Pd electrode towards negative potential direction. It increased the hydrogen evolution efficiency of Pd electrode remarkably. At the potentials - $1.1 \mathrm{~V}$, $1.2 \mathrm{~V},-1.25 \mathrm{~V}$ and $-1.3 \mathrm{~V}$, currents for Pd + Mo system found 1.44, 1.25, 1.20, 1.23 times higher than those of Pd electrode. Mo also showed hydrogen migratory role to the fraction of Pd surface covered by it. Hydrogen evolution reactions (HER) over Pd and Pd + Mo surfaces seemed followed similar mechanisms. Tafel plots for the HER for both the systems showed two Tafel regions. Exchange current density values $\left(i_{o}\right)$ for the low and high overpotential regions of Pd + Mo system showed 2.85 times and 1.29 times higher values than those of Pd electrode.
\end{abstract}

Keywards: Pd, Pd-Mo, Hydrogen evolution efficiency, Hydrogen evolution reactions (HER) 


\section{Introduction}

Hydrogen is a clean and nonpolluting fuel. It can diverse the present energy supply sources of transportation and can reduce the pollution linked to the fossil fuels. It can also be used in fuel cell to produce electricity, in household works where natural gas is using and in cooling systems in view to the depletion of ozone layer (Kreuter and Hofman 1998, Aki et al. 2006). In order to get this clean and sustainable energy sufficiently via nonpolluting means, scientists have focused on installing industrial electrolyzer (Giz et al. 1990 and Kaninski et al. 2006). In response, recently investigations on the improvement of well known electrodes by chemical means and in parallel searching of effective electrodes for the same purpose have drastically increased.

Pd is mostly investigated and well-known electrode of an electrolyzer. Its basic cathodic reaction is the hydrogen evolution reaction (HER) (Jakic et al. 1993). Hydrogen evolution capability of an electrode depends on various factors (Jakic et al. 1998). There are no materials in practical that can cover all the criterion of a standard electrode for hydrogen evolution. Pd is an expensive metal. In order to lower the cost of this electrode as well as electrolyzer, in the mean time hydrogen evolution efficiencies of PdAg (Vijh and Belanger 1986), Pd-Ni (Vracar et al. 1998), Pd-P (Podesta and Pittai 1997), etc. have been carried out. Although, a lot of improvements of Pd based cathodes had done but still research on the Pd electrode has been going on (Bokris and Minevski 2006). The aim of the most current investigations is to understand the hydrogen evolution reaction mechanism in absence and presence of additives those have capability of modifying the electrode surface and therefore the electrolysis efficiency (Jaksic et al. 1990, 1993, Bokris and Minevski 2006). Additive EDTA and Co-tris complex have been using to modify the surfaces of Pd, Pt, Au and Rh electrodes (Jaksic et al. 1990, 1993, 1994). Thiourea found able to modify the Au electrode surface (Vandeberg and Johnson 1993). EDTA and thiourea have found effective in modifying the iron oxide electrode (Periasamy et al. 1996).

Mo and Fe were tested to improve the capability of Ni electrodes (Brossard, 1991). It has been found that they improved the $\mathrm{Ni}$ electrode surface remarkably for hydrogen and oxygen evolution reactions. Recently, it has been reported that on alloying of Mo with $\mathrm{Ni}$, hydrogen evolution efficiency of $\mathrm{Ni}$ electrode remarkably increased (Raj and Venkatesan, 1998 and Kawashima et al. 1999). Deposited Mo on Ni remarkably increased its hydrogen evolution efficiency (Huot and Brossard 1998). It is well known that the mechanism of hydrogen evolution over $\mathrm{Ni}$ and Pd electrode surfaces is not so different in nature (Kibria et al. 1995 and Jaksic et al. 1993). In this sense, it is reasonable to assume that deposited Mo over Pd 
electrode may improve the hydrogen evolution efficiency of Pd electrode. Moreover, Pd is capable to evolve hydrogen at lower potentials than Ni (Giz et al. 1990). If Mo improves the capability of Pd electrode, then the technique will be more economical for hydrogen production and electrolyzer. In order to clear the fact and to understand the mechanism of improvement if any, the present study program has been taken to investigate on the electrochemical redox behavior, hydrogen evolution efficiency and reaction kinetics of Pd electrode in absence and presence of Mo. Study in alkaline electrolyte medium is preferred because corrosion of electrode materials is more easily controllable in this medium than the acidic medium (Kibria et al. 1995, Kreuter and Hofman 1998).

\section{Materials and Methods}

Palladium plate of purity $99.9 \%$ was purchased from the Tanaka Precious Metal Company, Japan. The plate was then rolled into a sheet of $1 \mathrm{~mm}$ thickness. To prepare the working electrode, the sheet was then cut into square size. It was then spot welded with a nickel wire. A glass pipe and epoxy resin then insulated the lower part of the connecting wire. The geometric surface area of the working electrode is $0.62 \mathrm{~cm}^{2}$. A coin type platinum plate of geometric surface area 4.1 $\mathrm{cm}^{2}$ was used as counter electrode. To remove any oxides present on the surface of the electrodes, these were chemically etched, polished by alumina paste and then rinsed with deionized water. The used electrolyte was 30wt.\%KOH solution.

A three-electrode cylindrical electrochemical cell designed and developed in the electrochemistry laboratory of the Atomic Energy Centre, Dhaka, was used for the experimental measurements. The indigenously prepared working electrode, counter electrode and the $\mathrm{Hg} / \mathrm{HgO} . \mathrm{OH}^{-}$reference electrode were immersed in $100 \mathrm{ml}$ electrolyte in triangular ways. The electrolyte was then freed from dissolved oxygen by bubbling $\mathrm{N}_{2}$ gas for 30 minutes. Cyclic voltammetric measurements were carried out by EG\&G PARC Model 362 potentiostat/ galvanostat and potential-current responses were recorded by EG\&G PARC Model RE $0089 \mathrm{X}-\mathrm{Y}$ recorder.

The Pd electrode was activated initially by maintaining a cathodic potential $-1.05 \mathrm{~V}$ for 30 minutes. The surface reaction behavior of the electrode was investigated in between the potential range $-1.05 \mathrm{~V}$ to $+0.75 \mathrm{~V}$ by applying a potential sweep rate $200 \mathrm{mV} / \mathrm{s}$. The effect of reaction time on the redox behavior of the electrode was carried out in the same potential range up to getting a stable condition. Hydrogen evolution efficiencies of Pd electrode were studied in between the potential ranges $-1.3 \mathrm{~V}$ to $+0.75 \mathrm{~V},-1.25$ $\mathrm{V}$ to $+0.75 \mathrm{~V},-1.2 \mathrm{~V}$ to $+0.75 \mathrm{~V}$ and -1.1 $\mathrm{V}$ to $+0.75 \mathrm{~V}$ at $100 \mathrm{mV} / \mathrm{s}$. About $30 \mathrm{ppm}$ of Mo was dissolved in the electrolyte in the 
form of sodium molybdate when necessary. Mo was deposited over the Pd electrode for 30 minutes at the potential $-1.50 \mathrm{~V}$ as followed earlier by the authors (Huot and Brossard 1988). Then the effect of reaction time and hydrogen evolution efficiencies were investigated on the Pd + Mo system as carried out on the Pd electrode.

For the determination of the kinetic parameters, i.e., Tafel slope, $b$, overpotential, $\eta$, and exchange current density, io, of the hydrogen evolution reactions (HER), continuous potential sweep method was used. Potential sweeps were carried out bv varving the cathodic potential $0.02 \mathrm{~V}$ in each scan towards positive potential direction from $1.50 \mathrm{~V}$ with a sweep rate of $10 \mathrm{mV} / \mathrm{s}$. The final positive potential was $+0.35 \mathrm{~V}$. The experiments were carried out for both the Pd and Pd + Mo system at room temperature.

\section{Results and Discussion}

Figure 1 shows the cyclic voltammograms appeared for the Pd electrode at 2, 10, 20, 35 and 50 minutes at scan rate of $200 \mathrm{mV} / \mathrm{sec}$ in between the potential range -1.05 to +0.75 $\mathrm{V}$ in $30 \mathrm{wt} . \% \mathrm{KOH}$ electrolyte at room temperature. It can be seen that three anodic

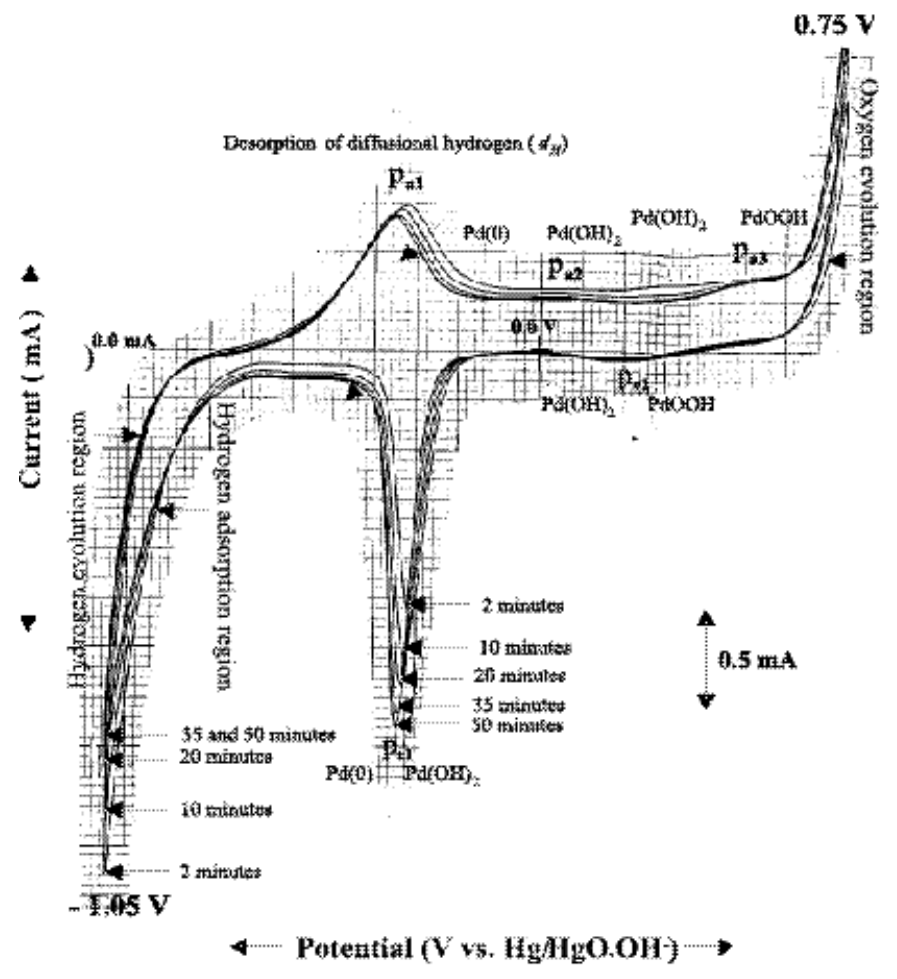

Fig. 1. Cyclic voltammograms of Pd electrode in 30wt.\% KOH electrolyte at 2, 5, 20, 35 and 50 minutes in between the potential range $-1.05 \mathrm{~V}$ to $+0.75 \mathrm{~V}$ at scan rate $200 \mathrm{mV} / \mathrm{s}$. 
peaks denoted as pa1, pa2 and pa3, and two cathodic peaks represented as pc1 and pc2 have appeared in the voltammograms. The peaks $\mathrm{p}_{\mathrm{a} 2}$ and $\mathrm{p}_{\mathrm{c} 1}$ and peaks pa3 and pc2 are couple of oxidation-reduction peaks. They have originated from the transformations of $\mathrm{Pd}(0) \leftrightarrow \mathrm{Pd}(\mathrm{OH})_{2}$ and $\mathrm{Pd}(\mathrm{OH})_{2} \leftrightarrow \mathrm{PdOOH}$, respectively. Transformation of $\mathrm{PdOOH} \rightarrow$ $\mathrm{PdO}_{2}$ oxide began at about the potential 0.62 V. Reduction and decomposition of $\mathrm{PdO}_{2} \rightarrow$ PdOOH caused oxygen evolution. Adsorption and simultaneous absorption of hydrogen became prominent at about the potential - $0.42 \mathrm{~V}$. Maximum hydrogen evolutions occurred from the set terminal potential - $1.05 \mathrm{~V}$. The anodic peak pa1 has originated from the desorption of diffusional hydrogen $(\mathrm{dH})$ absorped in the Pd lattice. It is well known that Pd can absorb enormous amount hydrogen in its octahedral lattice interstices (Kibria and Sakamoto 1997). Reduction peak pc1 related to the Pd(II) $\rightarrow$ $\operatorname{Pd}(0)$ transformation and pa1 related to $d_{H}$ showed remarkable currents. The shape of the presently observed voltammograms looks like to that reported for the Pd electrode in $0.1 \mathrm{M} \mathrm{KOH}$ at the scan rate 200 $\mathrm{mV} / \mathrm{s}$ (Jaksic et al. 1993).

With increasing the cycling times, the oxidation-reduction peak currents and potentials and the hydrogen and oxygen evolution efficiencies varied remarkably. It is notable that currents for the hydrogen and oxygen evolutions correspond to their evolution efficiencies (Giz et al. 1990 and Jaksic et al. 1998).
The observed remarkable variations are as follows: (i) current for the oxygen evolution gradually increased, (ii) current for the $\operatorname{Pd}(0)$ $\leftarrow \operatorname{Pd}(\mathrm{OH})_{2}$ transformation gradually increased, (iii) currents for the hydrogen evolution and $\mathrm{d}_{\mathrm{H}}$ gradually decreased, and (iv) peak potentials for the $\mathrm{Pd}(0) \leftarrow \mathrm{Pd}(\mathrm{OH})_{2}$ transformation and $\mathrm{d}_{\mathrm{H}}$ gradually moved to the negative potential direction. It can be seen that the rate of increase in current for the $\mathrm{Pd}(0) \leftarrow \mathrm{Pd}(\mathrm{OH})_{2}$ transformation per unit time gradually decreased. At 2 minutes, the average value is $0.65 \mathrm{~mA} / \mathrm{min}$ whereas it decreased to $0.05 \mathrm{~mA} / \mathrm{min}$ and $0.03 \mathrm{~mA} / \mathrm{min}$ at 35 and 50 minutes, respectively. At 2 minutes, hydrogen evolution current is $2.75 \mathrm{~mA}$ and it reached to a const value $2.1 \mathrm{~mA}$ at 35 and 50 minutes. For $\mathrm{d}_{\mathrm{H}}$, a constant current value $0.59 \mathrm{~mA}$ and constant potential value $0.35 \mathrm{~V}$ have appeared at these periods. The potential differences for the $\operatorname{Pd}(0) \leftarrow$ $\mathrm{Pd}(\mathrm{OH})_{2}$ transformation between those periods is less than $5 \mathrm{mV}$. It informs that after 35 minutes the Pd electrode surface reached to a stable condition.

Increase in current for $\mathrm{Pd}(0) \leftarrow \mathrm{Pd}(\mathrm{OH})_{2}$ transformation indirectly informs the increase in thickness of $\mathrm{Pd}(\mathrm{OH})_{2}$ layer over the electrode surface with time. This is the reduction process. Although increase in current for its corresponding oxidation process has not appeared remarkably, the increased Pd(II) layer consecutively transformed to $\mathrm{Pd}(\mathrm{III})$ and then $\mathrm{PdO}_{2}$ which caused higher oxygen evolution efficiency. Movement of 
peak for $\mathrm{Pd}(0) \leftarrow \mathrm{Pd}(\mathrm{OH})_{2}$ transformation towards negative potential direction means the Pd surface freed from $\mathrm{Pd}(\mathrm{OH})_{2}$ later. So, the hydrogen adsorption potential region decreased and comparatively lower amount of hydrogen adsorped over the $\operatorname{Pd}(0)$ surface which is the initial and mandatory step of the hydrogen evolution reactions (HER). It is well known that hydrogen can adsorped only on the $\mathrm{M}(0)$ surface where $\mathrm{M}$ represents metal (Jaksic et al. 1998). This movement of potential also affected the diffusion of hydrogen into the palladium lattice interstices that caused the movement of the potential of $d_{H}$ towards negative potential direction. From the above findings it is understandable that if the hydrogen adsorption region of Pd electrode can increase by additives then its hydrogen evolution efficiency will increase.

Fig. 2 shows the cyclic voltammograms obtained for the Pd + Mo system at 2, 10 and 20 minutes at scan rate of $200 \mathrm{mV} / \mathrm{sec}$ in between the potential range -0.90 to +0.75 $\mathrm{V}$ in $30 \mathrm{wt} \% \mathrm{KOH}$ electrolyte at room temperature. It may be seen that the shape of the voltammograms is analogous to that appeared for the Pd electrode (Fig. 1). On comparing the voltammograms with those observed for Pd electrode, it is clear that no

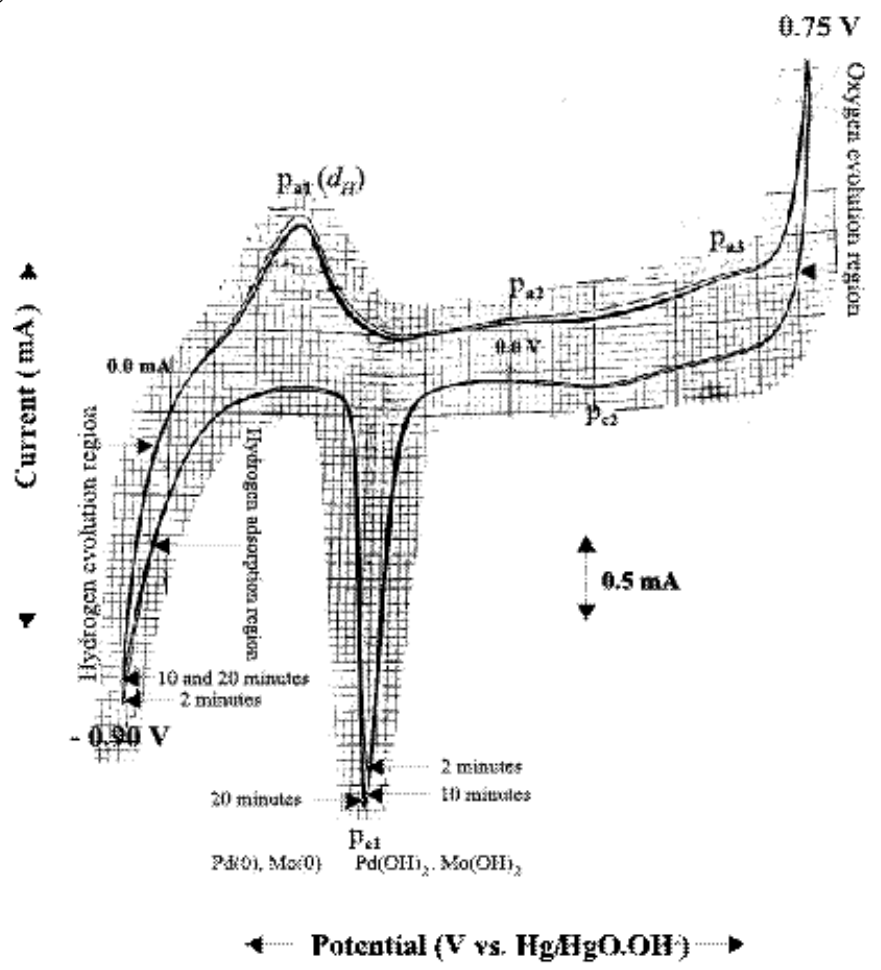

Fig. 2. Cyclic voltammograms of Pd + Mo system (Mo deposited Pd electrode) in 30wt.\%KOH electrolyte at 2, 10 and 20 minutes in between the potential range -0.90 to $+0.75 \mathrm{~V}$ at scan rate of $200 \mathrm{mV} / \mathrm{sec}$. 
new redox peaks have originated, current for the peak relevant to $\mathrm{Pd}(0) \leftarrow \mathrm{Pd}(\mathrm{OH})_{2}$ transformation is remarkably high, the movement of hydrogen adsorption and absorption region to the negative potential direction is negligible, the electrode system became stable earlier, hydrogen evolution current is higher, etc. These differences between them occurred obviously due to the modification of the Pd electrode surface by deposited Mo. Current for $\mathrm{Pd}(0) \leftarrow \mathrm{Pd}(\mathrm{OH})_{2}$ transformation related peak at the stable condition of electrode is about $2.55 \mathrm{~mA}$ and it is more than 1.4 times higher than that appeared for the Pd electrode. It indicates that Mo has successfully deposited over the Pd electrode surface by the adopting deposition procedure (Huot and Brossard 1988). The oxidized $\mathrm{Mo}(\mathrm{OH})_{2}$ species transforms to $\mathrm{Mo}(0)$ state by the reduction step $\mathrm{Mo}(0) \leftarrow \mathrm{Mo}(\mathrm{OH})_{2}$ at the same potential of $\mathrm{Pd}(0) \leftarrow \mathrm{Pd}(\mathrm{OH})_{2}$ transformation. It occurred probably due to the predomination of Pd over Mo. Such a predomination of a metal component over other usually observed during the electrochemical redox investigations of metal alloys (Jaksic et al. 1998). The electrode system became stable after 10 minutes. This time period is 3.5 folds faster than that observed for the Pd electrode. It informs that deposited Mo increased the rate of redox reactions. The hydrogen evolution current is almost equal to that appeared for the Pd electrode though the applying negative potential is $0.15 \mathrm{~V}$ lower. It indicates that deposited Mo may increase the hydrogen evolution efficiency of Pd electrode remarkably. Moreover, Mo may increase the rate of hydrogen evolution reaction and change the values of hydrogen evolution reaction kinetics.

Fig. 3 shows the cyclic voltammograms appeared for the Pd electrode in between the potential ranges $-1.30 \mathrm{~V}$ to $+0.75 \mathrm{~V},-1.25$ $\mathrm{V}$ to $+0.75 \mathrm{~V},-1.20 \mathrm{~V}$ to $+0.75 \mathrm{~V}$ and -1.10 $\mathrm{V}$ to $+0.75 \mathrm{~V}$ at scan rate $100 \mathrm{mV} / \mathrm{s}$ at the stable condition of the electrode. It can be seen that currents for the hydrogen evolution and $\mathrm{d}_{\mathrm{H}}$ gradually increased with increasing the negative potential value but those of the $\mathrm{Pd}(0) \leftarrow \mathrm{Pd}(\mathrm{OH})_{2}$ transformation remained almost constant. The observed hydrogen evolution current at $-1.1 \mathrm{~V}$ is $4.5 \mathrm{~mA}$. Hydrogen evolution currents appeared at $1.2 \mathrm{~V},-1.25 \mathrm{~V}$ and $-1.3 \mathrm{~V}$ are 2.9, 4.7 and 8.3 times higher than that observed at $-1.1 \mathrm{~V}$. Increase in corresponding currents of $\mathrm{d}_{\mathrm{H}}$ are 2.4, 4.0 and 6.4 times higher than that appeared at the potential range $-1.1 \mathrm{~V}$ to + $0.75 \mathrm{~V}$. Increase in currents for both the hydrogen evolution and $d_{H}$ is preserving a close relationship by maintaining a ratio about 1:0.33, 1:0.28, 1:0.28 and 1:0.25. When hydrogen evolution efficiency increased simultaneously hydrogen absorption/diffusion capability also increased. Peak potential for the $d_{H}$ gradually moved to the positive potential direction. Peak potential for $\mathrm{Pd}(0) \leftarrow \operatorname{Pd}(\mathrm{II})$ transformation gradually moved to the negative potential direction. It informs that with increasing the working potential range, hydrogen adsorption and 


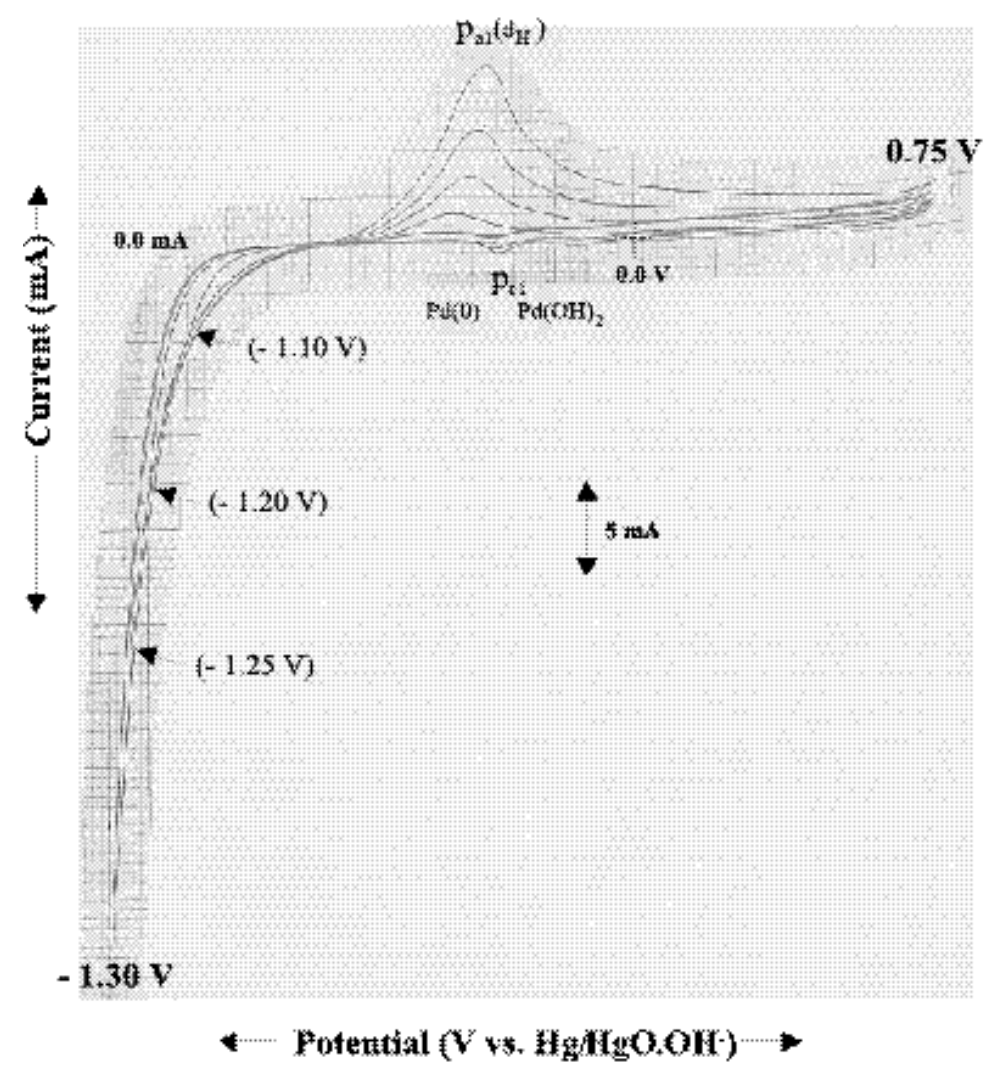

Fig. 3. Cyclic voltammograms of Pd electrode in $30 \mathrm{wt} . \% \mathrm{KOH}$ electrolyte in between the potential ranges $-1.30 \mathrm{~V}$ to $+0.75 \mathrm{~V},-1.25 \mathrm{~V}$ to $+0.75 \mathrm{~V},-1.20 \mathrm{~V}$ to $+0.75 \mathrm{~V}$ and $-1.10 \mathrm{~V}$ to $+0.75 \mathrm{~V}$ at scan rate $100 \mathrm{mV} / \mathrm{s}$.

absorption region moved to the negative potential value. Such a behavior decrease the hydrogen evolution efficiency.

Fig. 4 shows the cyclic voltammograms obtained for the Pd + Mo system in between the potential ranges $-1.30 \mathrm{~V}$ to $+0.75 \mathrm{~V}$, $1.25 \mathrm{~V}$ to $+0.75 \mathrm{~V},-1.20 \mathrm{~V}$ to $+0.75 \mathrm{~V}$ and $-1.10 \mathrm{~V}$ to $+0.75 \mathrm{~V}$ at scan rate $100 \mathrm{mV} / \mathrm{s}$ at the stable condition of the electrode. It can be seen that currents for the hydrogen evolution and $\mathrm{d}_{\mathrm{H}}$ gradually increased with increas ing the negative potential value. Current for the $\mathrm{M}_{\mathrm{Pd}, \mathrm{Mo}}(0) \leftarrow \mathrm{M}_{\mathrm{Pd}, \mathrm{Mo}}(\mathrm{OH})_{2}$ transformations remained almost constant as observed for the Pd electrode. The observed hydrogen evolution current at $-1.1 \mathrm{~V}$ is $6.5 \mathrm{~mA}$. Hydrogen evolution currents appeared at $1.2 \mathrm{~V},-1.25 \mathrm{~V}$ and $-1.3 \mathrm{~V}$ are 2.5, 3.9 and 7.1 times higher than that observed at $-1.1 \mathrm{~V}$. Increase in corresponding currents of $\mathrm{dH}$ are 1.9, 2.7 and 3.4 times higher than that appeared at the potential range $-1.1 \mathrm{~V}$ to + 


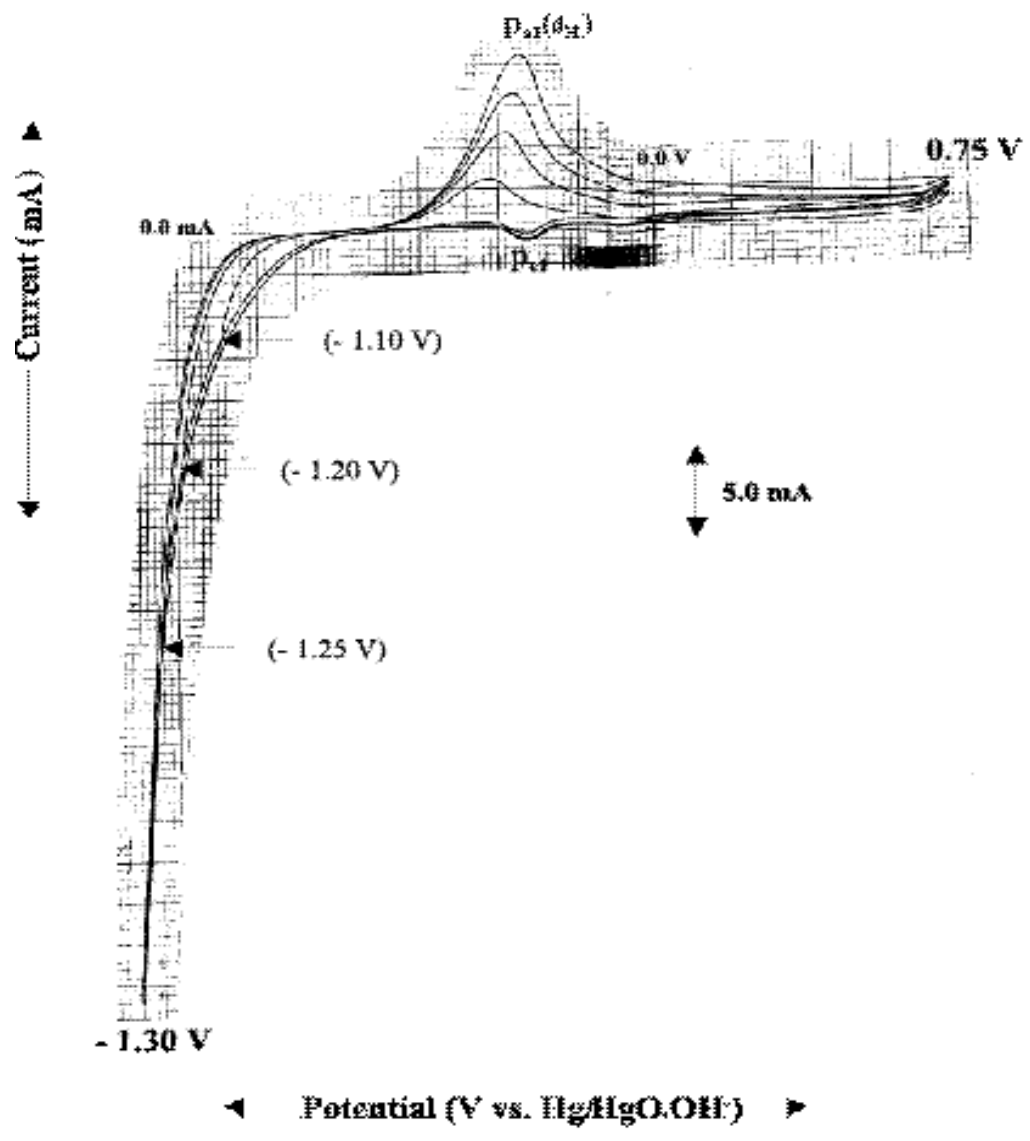

Fig. 4. Cyclic voltammograms of Pd + Mo system in 30wt.\% KOH electrolyte in between the potential ranges $-1.30 \mathrm{~V}$ to $+0.75 \mathrm{~V},-1.25 \mathrm{~V}$ to $+0.75 \mathrm{~V},-1.20 \mathrm{~V}$ to $+0.75 \mathrm{~V}$ and $-1.10 \mathrm{~V}$ to $+0.75 \mathrm{~V}$ at scan rate $100 \mathrm{mV} / \mathrm{s}$.

$0.75 \mathrm{~V}$. Observed hydrogen evolution efficiencies are $1.44,1.25,1.20,1.23$ times higher than those observed for the Pd electrode at $-1.1 \mathrm{~V},-1.2 \mathrm{~V},-1.25 \mathrm{~V}$ and $-1.3 \mathrm{~V}$, respectively. On the other hand currents for $\mathrm{d}_{\mathrm{H}}$ are 2.1, 1.64, 1.4 and 1.1 times higher than those observed for Pd electrode from lower to higher potential ranges. Increase in currents for both the hydrogen evolution and $\mathrm{d}_{\mathrm{H}}$ is showing ratios $1: 0.48,1: 0.36,1: 0.32$ and 1:0.23. Although, the ratios are little different than those observed for the Pd electrode, it informs that deposited Mo is enhancing both the hydrogen adsorption and absorption capability of Pd electrode. It is notable that Mo has no capability to absorb hydrogen in its lattice interstices as $\mathrm{Pd}$ (Lewis 1967). It indicates that a distinct mechanism than Pd occurred on the surface in increasing the amount of diffused hydro- 
gen and it will be described later.

It can be seen that the peak potential for $\mathrm{M}_{\mathrm{Pd}, \mathrm{Mo}}(0) \leftarrow \mathrm{M}_{\mathrm{Pd}, \mathrm{Mo}}(\mathrm{OH})_{2}$ transformations remained constant and the value is $-0.33 \mathrm{~V}$. This behavior is quite different from that observed for the Pd electrode where peak potential moved towards negative potential direction with increasing working potential ranges. From the Fig. 3, it can be seen that while cycling the Pd electrode in between the potential range $-1.3 \mathrm{~V}$ to $+0.75 \mathrm{~V}$, the observed peak potential values for the $\operatorname{Pd}(0)$ $\mathrm{Pd}(\mathrm{II})$ transformation is $-0.35 \mathrm{~V}$. On the other hand, the Pd electrode showed peak potential for $\mathrm{d}_{\mathrm{H}}$ at $-0.36 \mathrm{~V}$. But in case of Pd + Mo system the same peak appeared at $0.34 \mathrm{~V}$. It can be said that due to addition of Mo, both the peaks moved more than $20 \mathrm{mV}$ positive potential values. Movement of the reduction peak for $\mathrm{M}_{\mathrm{Pd}, \mathrm{Mo}}(0) \leftarrow \mathrm{M}_{\mathrm{Pd}, \mathrm{Mo}}(\mathrm{OH})_{2}$ transformations towards positive potential direction than $\mathrm{Pd}(0) \mathrm{Pd}(\mathrm{II})$ transformation is the reason of increase in hydrogen evolution current. As a result, more hydrogen easily adsorbed on the electrode surface and simultaneously more hydrogen diffused in the lattice interstices.

The role of additive Mo in increasing hydrogen evolution efficiency of Pd electrode can be described as follows. Rowland (1971) at first reported the benefit of deposited fresh metals over noble metals, in particular iron and nickel on to the cathode in increasing the isotope separation factor in electrolytic heavy water production while the HER in progress with the objective of entraining impurities beneath the continuously growing surface. The impurity metals form a fraction of layer over the electrode surface and shield it to convert to higher states. In the present case, Mo ions present in the vicinity of the Pd electrode surface deposits over it as $\mathrm{Mo}(0)$ state and thereby covers a fraction of the $\operatorname{Pd}(0)$ electrode surface and prevents the covered surface from redox transformations. Then both the exposed $\operatorname{Pd}(0)$ and $\operatorname{Mo}(0)$ present on the surface adsorped hydrogen. It seems that deposited $\operatorname{Mo}(0)$ functioned as scavenger and also as hydrogen migrator (Rowland 1971 and Jaksic et al. 1993). Adsorped hydrogen instantly migrated from the $\mathrm{M}(0)$ surface to the $\operatorname{Pd}(0)$ surface covered by it. This is one of the reasons of increasing the diffused hydrogen in the palladium lattice than the Pd electrode.

In order to determine the kinetic parameters of the hydrogen evolution reactions (HER) occurred over Pd and Mo deposited Pd surfaces, hydrogen evolution currents ( $i$ values) at different potential ranges were determined. The investigated potential ranges were in between $-1.50 \mathrm{~V}$ to $0.35 \mathrm{~V}$. The kinetic parameters- the exchange current density (io) and Tafel slope (b), were found out from the Tafel plot drawn by plotting overpotential $(\eta)$ against logi. The Tafel plots for Pd and Pd + Mo systems are shown in Fig. 5. It can be seen that the Tafel plots 

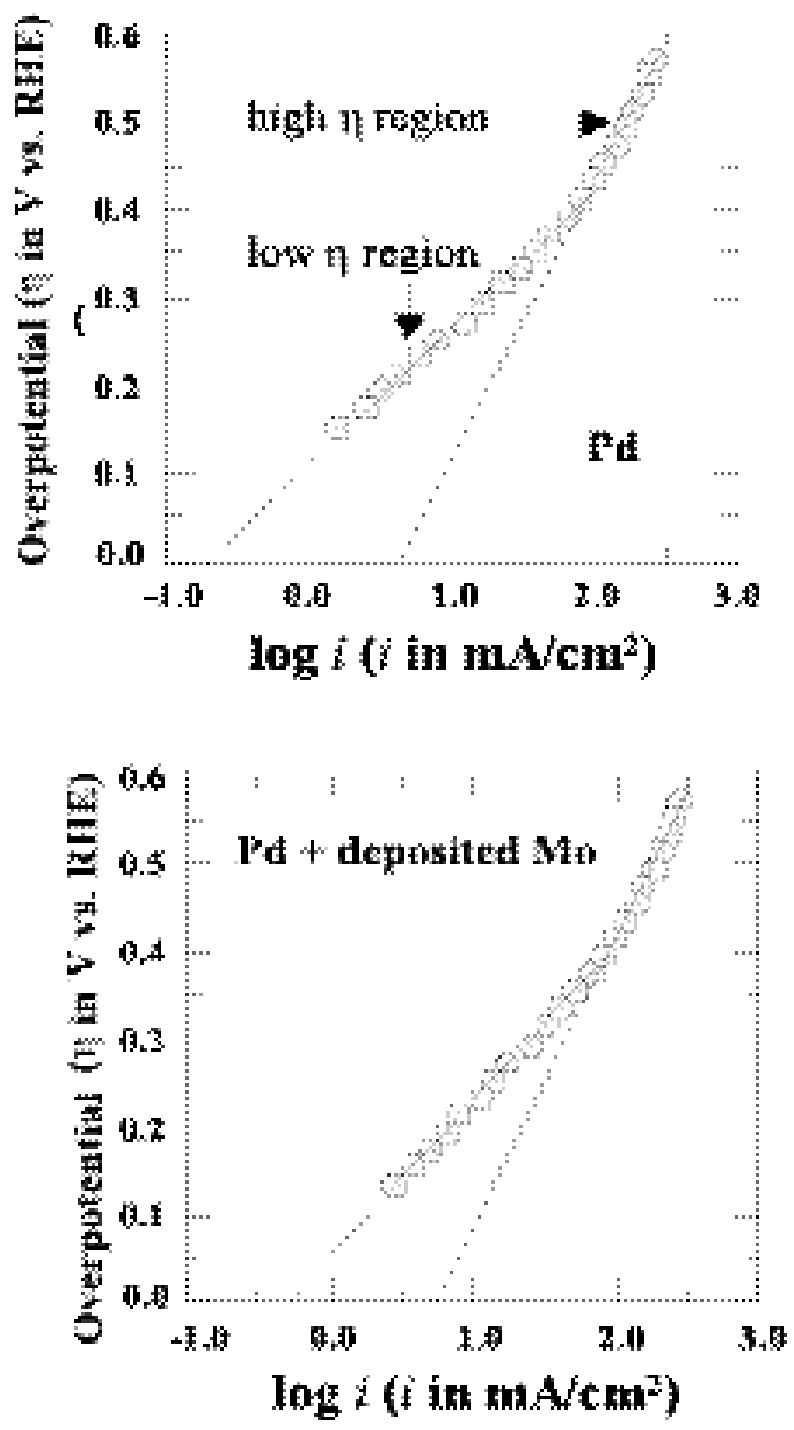

Fig. 5. Tafel plots for the hydrogen evolution reactions (HER) of Pd and Pd + Mo systems in $30 \mathrm{wt} . \% \mathrm{KOH}$ electrolyte at room temperature.

show two well-defined Tafel regions as that observed for Ni (Kibria et al. 1995), Pd and Pd based alloys (Vijh and Belanger 1986, Podesta and Piatti 1997) and Ni-Mo (Raj and Venkatesan 1988). The regions standing in the Tafel plots at low and high overpotentials are known as low $\eta$ and high $\eta$ regions. The kinetic parameters and as well as $i$ values appeared at the overpotential $\eta=0.3 \mathrm{~V}$ are also evaluated from the Tafel plots and sum- 
marized in Table I. From the Table, it can be seen that io values for Pd + Mo systems are higher than those of Pd electrode. In case of $\mathrm{Pd}+$ Mo system, io value for low h region is about 2.85 times higher than that of Pd. For high $\mathrm{h}$ region it is 1.29 times higher. At $\eta=$ $0.3 \mathrm{~V}, \mathrm{Pd}+$ Mo system showed the higher current density and it is about 53\% higher than that appeared for the Pd electrode. It signifies that dissolved and deposited Mo can be used in an electrolyzer having $\mathrm{Pd}$ electrode in improving its hydrogen evolution efficiency remarkably. hydrogen adsorption on the Pd and Pd + Mo surfaces namely water reduction with hydrogen adsorption known as Volmer step. To evolve hydrogen, two parallel competitive steps- electrochemical known as Heyrovsky step and chemical known as Tafel step followed the Volmer step. The mechanisms can be represented as:

Volmer step:

$[\mathrm{Pd}]+\mathrm{H}_{2} \mathrm{O}+\mathrm{e}=[\mathrm{Pd}] \mathrm{H}_{\mathrm{ads}}+\mathrm{OH}^{-} \ldots \ldots \ldots$.

$[\mathrm{Pd}+\mathrm{Mo}]+\mathrm{H}_{2} \mathrm{O}+\mathrm{e}=[\mathrm{Pd}+\mathrm{Mo}] \mathrm{H}_{\mathrm{ads}}+\mathrm{OH}^{-} \ldots$ (1a)

Table I. Tafel parameters for the hydrogen evolution reactions (HER) of Pd and Pd + Mo system (Mo deposited Pd) in 30wt.\% KOH electrolyte at room temperature

\begin{tabular}{l|c|c|c}
\hline System & Parameters & Low $\eta$ region & High $\eta$ region \\
\hline Pd & $i_{o}\left(\mathrm{~mA} / \mathrm{cm}^{2}\right)$ & 0.19 & 4.07 \\
& $b(\mathrm{mV} / \mathrm{dec})$ & 151 & 312 \\
& $i\left(\mathrm{~mA} / \mathrm{cm}^{2}\right)$ at $\eta=0.3 \mathrm{~V}$ & 17.25 & $\mathrm{X}$ \\
\hline Pd + Mo & $i_{o}\left(\mathrm{~mA} / \mathrm{cm}^{2}\right)$ & 0.54 & 5.25 \\
& $b(\mathrm{mV} / \mathrm{dec})$ & 171 & 351 \\
& $i\left(\mathrm{~mA} / \mathrm{cm}^{2}\right)$ at $\eta=0.3 \mathrm{~V}$ & 26.36 & $\mathrm{x}$ \\
\hline
\end{tabular}

From the experimental observations and findings, it is possible to understand the mechanism of hydrogen evaluation reaction (HER) over the Pd and Pd + Mo surfaces in $30 \mathrm{wt} . \% \mathrm{KOH}$ electrolyte. In absence and presence of Mo, the mechanism of hydrogen evaluation reactions (HER) obviously followed like trends in 30wt.\%KOH electrolyte because Mo enhanced hydrogen adsorption over the Pd surface. It seems that HER proceeded via three steps involving atomic
Heyrovsky step:

$[\mathrm{Pd}] \mathrm{H}_{\mathrm{ads}}+\mathrm{H}_{2} \mathrm{O}+\mathrm{e}=\mathrm{H}_{2}+[\mathrm{Pd}]+\mathrm{OH}^{-}$

$[\mathrm{Pd}+\mathrm{Mo}] \mathrm{H}_{\mathrm{ads}}+\mathrm{H}_{2} \mathrm{O}+\mathrm{e}=\mathrm{H}_{2}+[\mathrm{Pd}+\mathrm{Mo}]+\mathrm{OH}^{-}$

Tafel step:

$2[\mathrm{Pd}] \mathrm{H}_{\mathrm{ads}}=2[\mathrm{Pd}]+\mathrm{H}_{2} \ldots \ldots \ldots \ldots \ldots \ldots$ (3)

$2[\mathrm{Pd}+\mathrm{Mo}] \mathrm{H}_{\mathrm{ads}}=[\mathrm{Pd}+\mathrm{Mo}]+\mathrm{H}_{2}$ 


\section{Conclusions}

In search of an efficient cathode system for an electrolyzer, detailed investigations have been carried out over Pd and Mo deposited Pd electrodes in 30wt.\%KOH electrolyte by cyclic voltammetry. Voltammetric studies confirmed that Mo was successfully deposited over the Pd electrode at the exerting potential - 1.50 V. Deposited Mo remarkably improved the hydrogen evolution efficiency of Pd electrode by stopping the nature of movement of hydrogen absorption-adsorption region towards negative potential direction. It delivered rapid stability to the electrode system. It also behaved as a hydrogen migratory element. Pd predominated over deposited Mo and suppressed it to reduce at the same potential value during the reactions $\mathrm{Pd}(0) \rightarrow \mathrm{Pd}(\mathrm{OH})_{2}$ and $\mathrm{Mo}(0) \rightarrow \mathrm{Mo}(\mathrm{OH})_{2}$. Hydrogen evolution reactions (HER) over the Pd and Mo deposited Pd surfaces followed like mechanisms. Deposited Mo remarkably changed the reaction kinetics values for HER noting the improvement of Pd electrode surface. Tafel plots for the HER of Pd and Pd + Mo systems showed like Tafel regions. Pd deposited Mo system showed about 3.0 times and 1.3 times higher $i_{o}$ values at the low and high $\eta$ regions than those of Pd electrode.

\section{Reference}

Aki, H. Yamamoto, S. Kongoh, J. Maeda, T. Yamaguchi, H. Murata, A. and Ishii, J. (2006) Fuel cells and energy networks of electricity, heat and hydrogen in residential area. Int. J. Hydrogen Energy 31: 967-980.

Bockris, J. O. M. and Minevski, Z. (2000) The mechanism of the evolution of hydrogen on palladium and associated internal damage phenomena. Int. J. Hydrogen Energy 25 (8): 747-765.

Brossard, L. (1991) Electrocatalytic performance for alkaline water electrolysis of $\mathrm{Ni}$ electrodes electrocoated with $\mathrm{Fe}$ or Fe/Mo. Int. J. Hydrogen Energy 16 (1): 13-21.

Giz, de. M. J. Silva, da. J. C. P. Ferreira, M. Machado, S. A. S. Ticianelli, E. A. Avaca, L. A. and Gonzalez, E. R. (1990) Progress on the development of activated cathodes for water electrolysis. Hydrogen Energy Progress 8 (1): 405-414.

Huot, J. Y. and Brossard, L. (1988) In situ activation of nickel electrode by sodium molybdate for hydrogen evolution. Surface and Coating Technology 34 : 373-382.

Jaksic, M. M. Johansen, B. Istic, M. and Tunold, R. (1990) Electrocatalytic in situ activation of noble metals for hydrogen evolution, Hydrogen Energy Progress 8 (1): 461-472.

Jaksic, J. M. Krstajic, N. V. Grgur, B. N.and Jaksic M. M. (1998) Hydridic and electrocatalytic properties of hypo-hyper-delectronic combinations of transition metal intermetallic phases. Int. J. Hydrogen Energy 23 (8): 667-681.

Jaksic, M. M. Johansen, B. and Tunold, R. (1993) Electrochemical behavior of Pd in acidic and alkaline solutions of heavy and regular water. Int. J. Hydrogen Energy 18 (2): 111-124. 
Jaksic, M. M. Johansen, B. and Tunold, R. (1994) Electrochemical behaviour of rhodium in alkaline and acidic solutions of heavy and regular water. Int. J. Hydrogen Energy 19 (1): 35-51.

Kawashima, A. Sakaki, T. Habazaki, H. and Hashimoto, K. (1999) Ni-Mo-O alloy cathodes for hydrogen evolution in hot concentrated $\mathrm{NaOH}$ solution. Materials Science and Engineering A, 267 (2): 246-253.

Kaninski, M. P. M. Stojic, D. L. Saponjic, D. P. Potkonjak. N. I. and Miljannic, S. S. (2006) Comparison of different electrode materials: Energy requirements in the electrolytic hydrogen evolution process. J. Power sources 157 (2): 758-764.

Kibria, M. F. Mridha, M. Sh. and Khan, A. H. (1995). Electrochemical studies of a nickel electrode for the hydrogen evolution reaction. Int. J. Hydrogen Energy 20 (6): 435440.

Kibria, A. K. M. F. and Sakamoto, Y. (1997) Hysteresis of pressure-composition and electrical resistance-composition relationships of palladium-hydrogen system. Materials Science and Eng. 49B: 227-232.

Kreuter, W. and Hofman, H. (1998) Electrolysis: The important energy transformer in a world of sustainable energy. Int. J. Hydrogen Energy 22 (8): 661-666.

Lewis, F. A. (1967) The palladium hydrogen system, Academic press, pp. 52.

Podesta, J.J. and Piatti, R.C.V. (1997) Amorphous Pd-P, Au-P, and Co-P alloys as cathode materials in alkaline solution for oxygen reduction. Int. J. Hydrogen Energy 22 (8): 753-758.

Periasamy, P. Babu, B. R. and Iyer, S. V. (1996) Cyclic voltammetric studies of porous iron electrodes in alkaline solutions used for alkaline batteries. J. Power Sources 58 : 3540.

Raj, A. I. and Venkatesan, V. K. (1988) Characterization of nickel-molybdenum and nickel-molybdenum-iron alloy coatings as cathodes for alkaline water electrolysers. Int. J. Hydrogen Energy 13 (4): 215223.

Rowland, P. R. (1971) The maximum theoretical electrolytic separation factor of $\mathrm{H}(\mathrm{D})$ and its application to real systems. $J$. Electroanal. Chem., 32 (1): 89-108.

Vandeberg, P. J. and Johnson, D. C. (1993) A study of the voltammetric response of thiourea and ethylene thiourea at gold electrodes in alkaline media. J. Electroanal. Chem., 362 : 129-139.

Vijh, A. K. and Belanger, A. (1986) Electrocatalysis of the hydrogen evolution reaction by metals and Pd-Ag alloys in relation to their electronic configuration. Int. $J$. Hydrogen Energy 11 (3): 147-151.

Vracar, L. J. Burojevic, S. and Krstajic, N. (1998) The surface processes at Pd-Ni in acid and alkaline solutions. Int. J. Hydrogen Energy 23 (12): 1157-1164.

Received : October, 03, 2007;

Accepted : December 04, 2007 